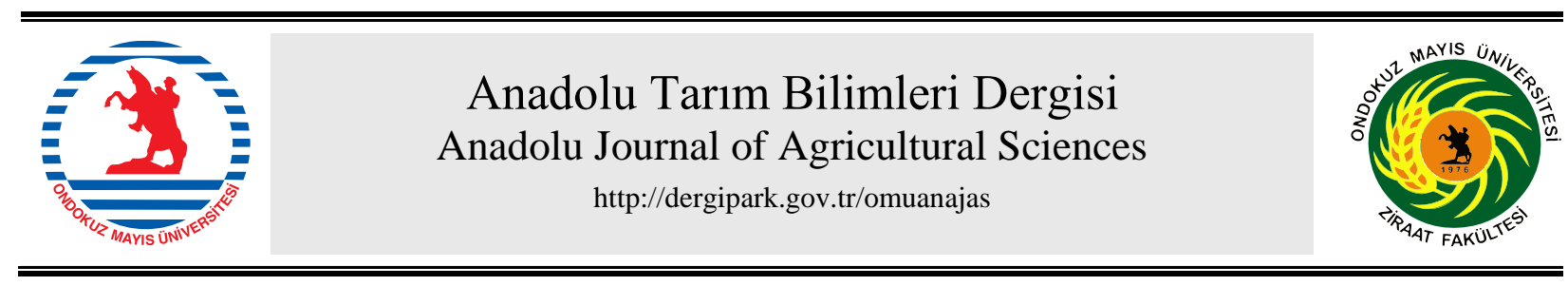

Araştırma/Research

Anadolu Tarım Bilim. Derg./Anadolu J Agr Sci, 36 (2021)

ISSN: 1308-8750 (Print) 1308-8769 (Online)

doi: 10.7161/omuanajas.670435

\title{
Sülfonilüre Grubu Herbisit Kullanılan Tekirdağ Tarım Alanlarından İzole Edilen Pseudomonas Türlerinin Karakterizasyonu
}

\author{
Mine Gül Şeker \\ Gebze Teknik Üniversitesi, Temel Bilimler Fakültesi, Moleküler Biyoloji ve Genetik Bölümü, Gebze, Kocaeli, TURKEY
}

*Sorumlu yazar/corresponding author: gul@gtu.edu.tr

Geliş/Received 06/01/2020 Kabul/Accepted 24/12/2020

\begin{abstract}
ÖZET
Toksik kirleticilerin biyolojik parçalanma ve toksik özelliklerinin gideriminde bakterilerin rolü çeşitli araştırmalarda ortaya konmuştur. Birçok toksik kimyasal gibi sülfonilüre grubu herbisitlerin de biyolojik olarak yıkımı konusu son yıllarda artan bir ilgiyle çalışılmaktadır. Bu çalışmada herbisitlerin yoğun olarak kullanıldığı buğday ve mısırın rotasyonlu ekildiği Tekirdağ tarım alanlarından Pseudomonas cinsinin temel özellikleri ile uyumlu 134 izolat saflaştırılmıştır. Bunların içinden yüksek herbisit konsantrasyonunda [500 $\left.\mathrm{mgL}^{-1}(\mathrm{w} / \mathrm{v})\right]$ hayatta kalan 45 izolat seçilmiștir. Seçilen izolatlar azotu fikse etme (42 izolat) ve fosfatı çözebilme (31 izolat), nitratı indirgeme (37 izolat), lipolitik (45 izolat) ve proteolitik (7 izolat) aktivite göstermiştir. Bunun yanında izolatların klasik biyokimyasal ve fizyolojik testler ile cins seviyesinde karakterizasyonu yapılmıştır. Bu izolatlardan 5 tanesi ise moleküler biyolojik yöntemler (16S rDNA dizi analizi) ile NCBI veri bankasındaki veriler ile karşılaştırılarak tür seviyesinde de tanımlanmıştır. Tanımlama sonuçları en yüksek benzerliğe (\%10099) sahip ilk üç eşleşmeye göre değerlendirilmiş ve izolatlar Pseudomonas cremicolorata, Pseudomonas parafulva; Pseudomonas putida (izolat 13); Pseudomonas baetica, Pseudomonas koreensis ve Pseudomonas helmanticensis (izolat 18); Pseudomonas plecoglossicida, Pseudomonas cremicolorata; Pseudomonas parafulva (izolat 28); Pseudomonas reidholzensis, Pseudomonas putida (izolat 38 ve 42 ) olarak tanımlanmıştır.
\end{abstract}

Characterization of Pseudomonas species isolated from agricultural areas applied with sulphonylurea group herbicides in Tekirdağ province

\section{ABSTRACT}

The role of bacteria in biological degradation and removal of toxic properties of pollutants has been set out in various studies. Like many toxic chemicals, biological degradation of sulphonylurea group herbicides has been studied with increasing interest in recent years. In this study, 134 isolates of Pseudomonas genus were isolated and purified from intense-herbicide applied agricultural areas, where wheat and corn were cultivated in rotation, in Tekirdağ province. Among these, 45 isolates which survived at high herbicide concentration $\left[500 \mathrm{mgL}^{-1}(\mathrm{w} / \mathrm{v})\right]$ were selected. The selected isolates showed the ability of nitrogen fixation (42 isolates) and phosphate solubilization (31 isolates), nitrate reduction (37 isolates), lipolytic (45 isolates) and proteolytic (7 isolates) activity. In addition, genotypic characterization of the isolates was performed by classical biochemical and physiological tests. Five of these isolates were identified at the species level by comparison with the data in the NCBI database by molecular biological methods (16S rDNA sequence analysis). The identification results were evaluated according to the first three matches with the highest identity rate (100-99\%) and isolates were identified as Pseudomonas cremicolorata, Pseudomonas parafulva, Pseudomonas putida (isolate 13); Pseudomonas baetica, Pseudomonas koreensis and Pseudomonas helmanticensis (isolate 18); Pseudomonas plecoglossicida, Pseudomonas cremicolorata; Pseudomonas parafulva (isolate 28); Pseudomonas reidholzensis and Pseudomonas putida (isolates 38 and 42).
Anahtar Sözcükler: Biyokimyasal ve moleküler karakterizasyon Degredasyon Pseudomonas Sulfonilüre 16S rDNA

Keywords: Biochemical and molecular characterization Degradation Pseudomonas Sulphonylurea 16SrDNA

(c) OMU ANAJAS 2021 


\section{Giriş}

Toprak neminin önemli olduğu kuru tarım yapılan ekim alanlarında, kültür bitkisi ile yabancı otlar arasındaki yaşam mücadelesi, yeterince yağış alan bölgelere göre daha fazladır (Donald, 1963). Yetersiz su, paylaşılması gereken besin miktarının sınırlılığı ve yetersiz ışık nedeniyle kültür bitkisi ve yabancı ot arasında bir rekabet ortamı oluşmaktadır. Yabancı otların allelopatik etkisi kültür bitkisinin kalite ve verimliliğini olumsuz etkilemektedir (Williams 1984; Waller 1989; Sözeri ve Solmaz 1996).

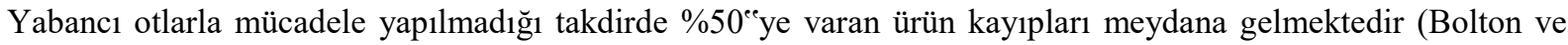
Hepworth 1972). Herbisitlerin yabancı ot mücadelesinde kullanımı, yeşil devrimin bir parçası olarak görülmüş olsa da, özellikle 80'li yıllardan itibaren, yoğun bir şekilde kullanımlarının negatif sonuçları ön plana çıkmaya başlamıştır. Sonrasında ise özellikle birim alana daha düşük miktarda etken madde içeren sülfonilüre grubu herbisitlerin piyasaya çıkmasıyla dünyada herbisit kullanımında azalma meydana gelmiştir. Son yıllarda dünya çapında yoğunlukla kullanılan Sülfonilüre grubu herbisitler, insan ve hayvan sağlı̆ğ üzerinde düşük toksisiteye sahip olmaları nedeniyle tercih edilmektedir. Bu grup herbisitler buğday, arpa, pirinç, soya fasulyesi, pamuk, patates ve mısır gibi ürünlerin yetiştiriciliğinde yabancı ot mücadelesi için dünya çapında kullanılan, geniş bir kimyasal herbisit grubudur (Blair ve Martin, 1988; Brown, 1990; Zhou ve ark., 2008). Her ne kadar birim alanda kullanılan herbisit miktarının tonaj bazında azalması sağlanmış olsa da zaman içerisinde bu grup herbisitlerin de diğerlerine benzer yan etkilerinin olduğu gözlenmiştir (Bellinder ve ark., 1994). Bu nedenle sülfonilüre grubu herbisitlerin de dâhil olduğu yabancı ot ilaçlarının toprakta aktif olarak bulunduğu veya kaldığı süre çok önemlidir (Kaur ve Brar, 2014). Bu süre, yabancı ot ile ekilen bitki arasındaki hayatta kalma mücadelesinde ekimi yapılan bitki lehine olacak şekilde sınırlı olmalıdır. Yabancı otun gelişiminin engellendiği süreçte herbisit parçalanmalı veya kalıntıları da dahil toprakta aktivitesini kaybederek kaybolabilmelidir (Zimdahl, 2007). Ancak sülfonilüre herbisitler özellikle alkali topraklarda uzun süre aktif olarak kaldıklarından, rotasyona tabi ekilen ikinci ürün bitkilerinde ciddi fitotoksisiteye neden olmaktadır (Kaur ve Brar, 2014). Bu durum ise çiftçilerin ikinci ürün olarak ekebileceği bitki tercihlerini sınırlandırmaktadır (Başaran, 2010).

Doğada bulunan tüm kirleticiler, dolaylı veya doğrudan insan sağlığını etkilemektedir. Bu sebeple, kirleticilerin mevcut sağlıklı çevreden bir an önce detoksifikasyon veya biyoremediasyon yolu ile uzaklaştırılması veya etkisiz hale getirilmesi, kirlilikle mücadelenin ana senaryosunu oluşturmaktadır. Bunun sağlanması için en önemli kaynak hiç kuşkusuz çevrede doğal olarak bulunan ve biyoremediasyon yeteneği olan mikroorganizmalardır (Wasi ve ark., 2013). Toksik kirleticilerin biyolojik parçalanma ve detoksifikasyonunda bakterilerin rolü birçok çalışmada belgelenmiştir (Johri ve ark., 1996; Wasi ve ark., 2011a, b). Bu konudaki ilk rapor Matsumura ve ark. (1976) tarafindan persistent pestisit hegzeklorosiklohekzan $(\mathrm{HCH})^{\prime}$ in Pseudomonas spp. izolatları tarafindan aerobik olarak parçalanması konusunda yapılmıştır. Daha sonralarda bu mikroorganizmanın $P$. paucimobilis olduğu, Wada ve ark. (1989) tarafından bildirilmiştir. Literatürde 2,4 D, karbamat gibi pestisitlerin, fenolik bileşiklerin, kathekol gibi pestisit ham maddelerinin, petrolyum hidrokarbonlarının, $\mathrm{Cd}, \mathrm{Cr}, \mathrm{Cu}$ gibi ağır metallerin, p-crezol, petrol hidrokarbonları gibi organik veya inorganik kirleticilerin parçalanması veya gideriminde etkin olan başta $P$. aeruginosa, $P$. acidovorans, $P$. flourescens ve $P$. putida olmak üzere pek çok Pseudomonas sp. türü bakteri rapor edilmiştir (Wasi ve ark., 2013). Pseudomonas cinsi bakteriler sahip oldukları biyoremediasyon ve parçalama yetenekleri sayesinde tarım ve çevre koruma uygulamalarında potansiyel kullanım alanlarına sahip mikroorganizmalardır.

$\mathrm{Bu}$ çalışmada, TNM ve NS etken maddeli herbisitlerin yoğunlukla kullanıldığı Tekirdağ İli, Süleymanpaşa ilçe sınırları içinde bulunan hububat ekim alanlarından alınan toprak örneklerinde biyoremediasyon ve biyolojik parçalama yeteneklerine sahip olan tarımsal uygulamalarda bitki dostu biyoformülasyonlar için aday Pseudomonas türü bakterilerin izolasyonu, saflaştırılması ve sülfonilüre herbisitleri biyolojik olarak parçalayabilme yeteneklerine sahip olanlarından seçilen izolatların mikrobiyolojik ve moleküler karakterizasyonları yapılmıştır.

\section{Materyal ve Yöntem}

\subsection{Toprak Örneklerin toplanması}

Tekirdağ İli Süleymenpaşa ilçe sınırları içinde bulunan ve örnekleme bölgesi olarak seçilen tarım arazilerinden, resmi izinler alındıktan sonra 2018 yılı Ekim ayında hasat sonrası tribenüron metil ve nikosülfüron kullanıldığı tespit edilen ve ekim nöbeti (münevebeli ekim) ile buğday ve mısır ekilen Yağcı, Osmanlı, Banarlı köyleri ve Süleymanpaşa /Gazioğlu Mahallesi'ndeki arazilerde bulunan hububat bitkilerinin rizosferinden $(10-30 \mathrm{~cm}$ derinlikten) ve tarla yüzey toprağından toplam 36 toprak örneği alınmıştır (Şekil 1).Toprak örnekleri temiz kâğıt havlulara sarılarak ağzı kilitli poşetler içerisinde taşınabilir araç buzdolabında laboratuvara getirilmiş̧ir. İzolasyon protokolünün uygulanmasına kadar $+4{ }^{\circ} \mathrm{C}$ soğuk odada saklanmıştır. 


\section{2 İolasyon, saflaştırma ve stokların hazırlanması}

Toprak örnekleri temiz filtre kağıtları üzerinde kurutulup iyice toz haline getirildikten sonra porselen süzgeçlerden elenerek, bitki örnekleri ise yaprak ve kök bölgesinden steril bistüri ucu yardımı ile kesilerek izolasyon için hazır hale getirilmiştir. Her bir örnekleme noktasına ait bitki ve toprak örnekleri şahit örnek olarak saklanmak üzere poşetlenerek $+4^{\circ} \mathrm{C}^{\prime}$ ta muhafaza edilmiştir.

\subsection{Rizosferik ve yüzey toprağı örneklerinden izolasyon}

Buzdolabında $\left(4+^{\circ} \mathrm{C}\right)$ saklanan toprak örneklerinden $1 \mathrm{gr}$ tartılmıştır. Örnekler yaklaşık $9 \mathrm{ml}$ steril peptonlu su içeren (zenginleştirme, adaptasyon ve çoğaltma için) tüplere aktarılarak vorteks ile karıştırılıp ve $30^{\circ} \mathrm{C}^{\prime}$ ta $24-48$ saat inkübe edilmiştir. Üreme görülen tüplerden 100 'er ul alınarak steril \%0.9' luk fizyolojik tuzlu su (FTS) içinde 10-110-7 arasında seri dilüsyonları yapılmıştır. İzolasyon protokolünde Pseudomonas seçici besiyeri olarak Cetremide Agar [(CA)- Jelatinden elde edilen Pepton $20.0 \mathrm{~g} / \mathrm{L}$; Magnezyum klorür $1.4 \mathrm{~g} / \mathrm{L}$; Potasyum sülfat $10.0 \mathrm{~g} / \mathrm{L}$ ] kullanılmıştır (Atlas, 2004). Hazırlanan $10^{-5}, 10^{-6}, 10^{-7}$ dilüsyonlarından $100 \mathrm{ul}$ alınıp CA besiyerine yayma ekim yapılarak, geç üreyen farklı Pseudomonas türlerinin izole edilebilmesi için ekim yapılan petri kapları $30^{\circ} \mathrm{C}^{\prime}$ ta 72 saat boyunca inkübe edilmiştir. CA besiyerinde inkübasyonun 24., 48. ve 72. saatlerinde petri kaplarında görülen farklı kolonilerden steril öze yardımıyla Nutrient Agar (NA) besiyerine saflaştıılmıştır. 24 saat inkübasyonun ardından petri kaplarında oluşan kolonilerden alınan örnekler lam üzerine yayılarak Gram boyama yöntemi ile boyanmıştır. Gram negatif basil formundaki izolatlar, izolasyon bölgelerine göre kodlandıktan sonra steril Nutrient Broth (NB) besiyerine inoküle edilerek 24 saatlik taze kültürleri hazırlanmıştır. Elde edilen taze kültürlerden, \%80' lik steril gliserol (\%50 v/v ) içinde $-20 \mathrm{ve}-80^{\circ} \mathrm{C}^{\prime}$ ta muhafaza edilmek üzere stok kültür hazırlanmıştır.

\subsection{Biyolojik parçalanma deneyleri}

Elde edilen tüm izolatların LB (Luria Bertani) sıvı besiyeri içinde $(\% 2 \mathrm{v} / \mathrm{v}) 24$ saatlik taze kültürleri hazırlanmıştır. Aynı besiyerinin agar formu ise tribenuron metil (Vesuper, 75 DF - \%75 aktif madde içeren suda eriyebilir toz formülasyon) ve nikosülfuron (Moonson, - $40 \mathrm{~g} / \mathrm{L}$ aktif madde içeren sıv1 formülasyonu) $500 \mathrm{mgL}^{-1}$ $(\mathrm{w} / \mathrm{v})$ final konsantrasyonunu içerecek şekilde ayrı ayrı hazırlanmıştır. İzolatların taze kültürlerinden bu besiyerlerine ekim yapılmıştır (Ma ve ark., 2009). İnoküle edilen izolatlar $30^{\circ} \mathrm{C}$ ' ta $24-48$ saat inkübe edilmiştir. İnkübasyon periyodunu takiben hayatta kalan ve görünür hale gelen koloniler kaydedilmiştir.

\section{5 İzolatların Genus seviyesinde klasik mikrobiyolojik testler ile tanımlanması}

Biyolojik parçalama testleri sonucunda yüksek herbisit konsantrasyonunda hayatta kalan koloniler oluşturabilen izolatlara Pseudomonasların genus seviyesinde tanımlanmasında tercih edilen Gram boyama, hareketlilik, oksidaz, floreskin ve piyosiyanin pigment varlı̆̆ının taranması, glukoz fermentasyonu, proteolitik ve lipolitik aktivite ve indol, metil kırmızısı, Voges-Preskauer, denitrifikasyon testleri gibi biyokimyasal ve fizyolojik testler ile nalidiksik asit, sefaloridin, penisilin $\mathrm{G}$, pimarisin antibiyotiklerine dirençliliğin tarandığı antibiyogram testi, $\mathrm{N}$ fiksasyonu, ve fosfat çözünürlüğü testleri Alexander ve Street, (2001)' e göre elde edilen tüm saflaştırılmış izolatlara (134 izolat) uygulanmıştır. Biyokimyasal karakterizasyonda genus seviyesinde Psedomonas'ların seçimi için genusu temsilen pozitif kontrol olarak P. aeruginosa ATCC 15692 kullanılmıştır.

\subsection{Seçilmiş izolatların moleküler biyolojik yöntemler ile tanımlanması}

Klasik biyokimyasal fizyolojik ve antibiyotik dirençlilik test sonuçlarına dayalı tanımlama testlerini takiben moleküler biyolojik (16S rDNA dizleme) yöntemler ile tanımlanmak üzere 5 izolat; glikozu iyi derecede fermente edebilen (izolat 13), iyi derecede PO4'lı bileşikleri çözebilen (izolat 18), iyi derecede proteolitik ve lipolitik aktiviteye sahip olmasının yanı sıra, iyi derecede PO4'lı bileşikleri çözebilen (28 no'lu izolat) ve bunların her ikisine de sahip (izolat 38 ve 42) izolatlardan seçilmiştir (Çizelge 1).

\subsubsection{DNA izolasyonu}

Seçilen izolatlardan DNA izolasyonu için $5 \mathrm{ml}$ LB besiyerinde \%2 (v/v) Pseudomonas sp. izolatlarının 24 saatlik taze kültürleri $30^{\circ} \mathrm{C}$ ’ta inkübe edilerek hazırlanmıştır. Taze kültürler 4500 g'de 20 dk santrifüj edilmiştir. Santrifüj sonrası elde edilen pelletlerden NucleoSpin ${ }^{\circledR}$ Microbial DNA İsolation Kit (Macherey-Nagel, Almanya) kullanılarak DNA izolasyonu gerçekleştirilmiştir. Elde edilen DNA' ların varlığı agaroz jelde gösterilerek, nanodrop (Thermo Scientific, Nanodrop Lite Spectrophotometer/USA) ile miktar tayinleri yapılmıştır. 


\subsubsection{Polimeraz Zincir Reaksiyonu ile 16 S rDNA dizisinin çoğaltılması}

İzolatların DNA'larından 16SrDNA bölgesinin eldesine ve çoğaltılmasına yönelik olarak Polimeraz Zincir Reaksiyonu (PZR) için reaksiyon karışımı hazırlanmıştır. Primer olarak $16 \mathrm{~S}$ rDNA gen bölgesine özgül 27F 5' AGA GTT TGA TCM TGG CTC AGA - 3' ve 1492 R 5' - TAC GGY TAC CTT GTT ACG ACT T - 3' evrensel primer çiftleri kullanılmıştır (Lane, 1991; Zhang ve ark., 2013). Reaksiyon toplam hacmi $50 \mu$ lolacak şekilde; $1 \mathrm{X}$ PZR Taq buffer, $0.2 \mu \mathrm{M}$ dNTP karışımı, $200 \mu \mathrm{M}, 0.5 \mu \mathrm{M}$ F ve R primer çiftleri, Taq polimeraz $1 \mathrm{u} / \mu 1$, kalıp DNA $<50$ ng ile hazırlanmış ve $50 \mu$ l'ye RNaz ve DNaz ari apirojen su ile tamamlanmıştır (https://www.uoftmedstore.com/pdfs/CrimsonTaq_MedStore.pdf). Termal döngü cihazı programı, ön denatürasyon $95^{\circ} \mathrm{C}$ 'ta $5 \mathrm{dk}$, denatürasyon $95^{\circ} \mathrm{C}$ ta $1 \mathrm{dk}$, bağlanma $58^{\circ} \mathrm{C}^{\prime}$ ta $1 \mathrm{dk}$, uzama $72^{\circ} \mathrm{C}$ ' ta $10 \mathrm{dk}$ olacak şekilde toplam 30 döngü olarak gerçekleştirilmiştir. PZR sonucu elde edilen yaklaşık 1500 baz çiftlik $16 \mathrm{~S}$ rDNA bölgesinin elde edildiği, \%1' lik agroz jelde $45 \mathrm{dk} 80 / 110$ V'ta yürütüldükten sonra görüntülenmiştir. PCR ürünleri Triogen (Almanya) firmasına dizi analizine gönderilmiştir. Çift yönlü olarak dizilenen 16S rDNA gen bölgeleri "revers complement programı" kullanılarak birleştirilmiş (https://www.genscript.com/sms2/rev_comp.html) tek bir dizi haline getirilmiştir. İzolatların 16srDNA gen bölgesine ait diziler NCBI Basic Local Alignment Search Tool çatısı altındaki Nucleotid BLAST programı kullanılarak veri bankasındaki diziler ile karşılaştırılmıştır (Altschul ve ark., 1997).

\section{Bulgular ve Tartışma}

\section{1 Örnekleme sonuçları}

Çalışma kapsamında 36 örnekleme bölgesinden alınan rizosferik ve yüzey toprak örneklerinden CA seçici besiyeri kullanılarak toplam 134 Pseudomonas izolatı elde edilmiştir.

\subsection{Biyolojik parçalanma deneyleri}

Biyolojik parçalanma deneyleri sonucunda NS' da üremeyen 4 izolat dışında tüm izolatlar biyolojik parçalanma testleri için NS ve TBM herbisit etken maddelerini $\left(500 \mathrm{mgL}^{-1}\right)$ içeren LB agarda gelişebilmiştirler.

\section{3 İzolatların Genus seviyesinde tanımlanması}

Elde edilen 134 izolata Gram boyama, hareketlilik, oksidaz, floreskin ve piyosiyanin pigment varlığının taranması glukoz fermentasyonu, proteolitik ve lipolitik aktivite ve indol, metil kırmızısı, Voges-Preskauer testleri, denitrifikasyon, $\mathrm{N}$ fiksasyonu, ve fosfat çözünürlüğü testleri gibi biyokimyasal ve fizyolojik testler ile nalidiksik asit, penisilin G, pimarisin antibiyotiklerine dirençliliğin tarandığı antibiyogram testi uygulandıktan sonra, 134 izolatın içinden yakın izolasyon noktalarından gelen ve benzer özelliklere sahip olanları ayrılarak, birbirinden farklı noktalardan izole edilen 45 izolat seçildi. Bu izolatlar için yukarıda adı geçen testler tekrarlanmıştır ve seçilen izolatlar azotu fikse etme (42 izolat) ve fosfatı çözebilme (31 izolat), nitratı indirgeme (37 izolat), lipolitik (45 izolat) ve proteolitik (7 izolat) aktivite göstermiş, sonuçlar Çizelge 1' de verilmiştir. Test sonuçlarına göre; 45 Gram negatif izolatın tamamı hareketli iken içlerinden 42 izolat oksidaz pozitif, 3 izolat ise oksidaz negatif olarak bulunmuştur. Piyosiyanin, floreskin pigmentlerinden birini veya her ikisini birden üreten 30 izolat tespit edilmiş, kalan 15 izolat herhangi bir pigment oluşturmamıştır. 11 izolat dişındaki tüm izolatlar (34 izolat) glukozu kullanmıştır. 7 izolat (3 tanesi güçlü olmak üzere) proteolitik aktivite gösterirken, tüm izolatlar (2 tanesi güçlü olmak üzere) lipolitik aktivite göstermiştir. Tüm izolatların Indol, Metil kırmızısı ve Voges Proskauer testleri negatif bulunmuştur. Nitratı nitrite indirgeyen izolat sayısı 37 iken 8 izolat negatif sonuç vermiştir. Bunun yanında aynı zamanda azotu fikse eden 42 izolat tespit edilmiş, bunlardan 9 izolat güçlü pozitif sonuç vermiştir. 3 izolat ise azotu fikse etmemiştir. 31 izolatın 14 tanesi güçlü fosfatı çözebilme yeteneği göstermiştir. Antibiyogram test sonuçlarına göre ise 16 numaralı izolat Penisilin G ye, 19 numaralı izolat ise Pimarisin antibiyotiklerine karşı hassas bulunmuştur. Aynı zamanda 29 numaralı izolat ise Penisilin G'ye karşı orta düzeyde (intermediate) hassas bulunmuştur. Kalan tüm izolatların nalidiksik asit, penisilin $\mathrm{G}$ ve pimarisin antibiyotiklerine karşı çoklu antibiyotik direncine sahip oldukları gözlemlenmiştir (Çizelge 1). ISO/TS 11059 uluslararası standardına (2017)'e göre Pseudomonasların seçiminde bu antibiyotikleri içeren besiyeri katkılarının kullanımı önerilmekte ve Pseudomonas türlerinin düşük membran geçirgenlikleri sebebiyle doğal olarak çoklu antibiyotik iç (intrinsic) direncine sahip oldukları bilinmektedir (Pachori ve ark., 2019). Elde edilen bulgular tür seviyesinde bu izolatların Pseudomonas sp. olduklarını desteklerken tür seviyesinde Pseudomonas aeruginosa'ya yaklaştırmıştır. 


\subsection{Moleküler Biyolojik yöntemler ile izolatların tanımlanması}

Söz konusu 5 izolata dair elde edilen dizilerin NCBI veri bankası benzerlik sonuçları izolatların; biyokimyasal ve fizyolojik test sonuçlarını doğrular nitelikte Pseudomonas sp. türlerine benzerlik göstermiştir (Çizelge 2). Bu çalışma kapsamında Tekirdağ ili, Süleymanpaşa ilçe sınırları içinde bulunan farklı tarım alanlarından izole edilen bakteriler genus seviyesinde hem klasik hem de moleküler tanı testleri ile Pseudomonas sp. olarak tanımlandı. Elde edilen izolatların, biyokimyasal karakterizasyon testleri sonucunda kontrol olarak kullanılan P. aeruginosa ATCC 15692 ile benzer özelliklere sahip olduğu gözlemlenmiştir. İlgili kontrol türüne görece farklı biyokimyasal özellikler gösteren izolatlar, moleküler testler ile Pseudomonas genusunun farklı türlerine BLAST analizi sonucunda yüksek benzerlik (\%99-100) göstermiştir (Çizelge 2). 13 numaralı izolat P. creimicolorata DSM 17059, P. parafulva NRBC 16636' ye \%100 benzerlik oranı ile benzerlik göstermiştir. 18 numaralı izolat $P$. beatica \%100, $P$. koreensis ve $P$. helmanticensis'e \%99 benzerlik oranı ile benzerlik göstermiştir. 28 numaralı izolat $P$. plecoglossicida NBRC 103162, P. cremoricolorata DSM 17059 ve $P$. parafulva NBRC 16636' e \%100 benzerlik göstermiştir. Otuzsekiz ve 42 numaralı izolatlar ise $P$. reidholzensis, $P$. putida NBRC 14164 ve $P$. putida ATCC 12633' aynı benzerlik yüzdesi (\%99) ile benzerlik göstermiştir. Son iki izolatın (38 ve 42 no' lu izolatlar) aynı bakteri türü olma ihtimalleri biyokimyasal test sonuçları ile de desteklenmektedir.

Onüç numaralı izolat özelinde araştırıldığında; $P$. cremicolorata ve P. parafulva'nın $P$. putida'dan filogenetik olarak dallanarak farklılaştığı ve yüksek akrabalık seviyesinde benzer oldukları bildirilmektedir (Peña ve ark., 2016). Her üç tür de Pseudomonas'ların genel özelliklerini (Gram- negatif- çubuk şeklinde hareketli, oksidaz ve katalaz pozitif) taşımasının yanısıra 16S rRNA gen dizilemesine göre de Pseudomonas genusunda konumlanmaktadırlar. Bu üç tür de suda çözünmeyen sarı pigment oluşturmakta düz, konveks ve kremsi koloni yapısı ile nutrient agar üzerinde karakterize olmaktadırlar (Uchino ve ark., 2001). Bu çalışma ile 13 numaralı izolat için elde edilen moleküler tanı sonuçlarına göre bu izolatın tüm genom dizilemesi gibi ileri moleküler yöntemler yaklaşımıyla tür seviyesinde tanımlanma sürecinin tamamlanabileceği görülmektedir. 18 numaralı izolat için yapılan literatür taramasında ilgili türün 2012 yılında López ve arkadaşları tarafından $P$. beatica isimlendirmesi ile yeni bir Pseudomonas türü olarak önerildiği görülmektedir. Diğer yandan bu türün Pseudomonas türlerinden jelatin hidrolizi, glukozdan asit oluşturma ve \%6 NaCl'de gelişebilme fenotipik karakteristikleriyle ayrıldığını ve virulans testlerinde dilbalığı patojeni olarak tanımladıklarını bildirmişlerdir. İlgili türün 16S rRNA dizi analizine göre P. koreensis (Kwon ve ark., 2003) ile yakın bir akrabalık ilişkisine sahip olduğu ve bu aşamada temel genler (housekeeping) ile (özellikle gyrB, rpoB, rpoD genleri) $P$. beatica' dan ayırımının daha net sonuçlar vereceği bildirilmiştir (RamirezBahena ve ark., 2014). $P$. helmanticensis 16S rRNA dizi analiz sonuçlarına göre, bu türün $P$. koreensis ve $P$. beatica'dan dallanarak farklılaştı̆̆ 1 belirtilmiş ve kesin bir sınıflandırma için yine temel genler bazında incelenmenin gerektiği ifade edilmiştir (Mitsutomi ve ark., 2017). Güçlü proteolitik ve lipolitik aktivitesi ile öne çıkan 28 numaralı izolatın benzerlik gösterdiği $P$. plecoglossicida ise tıpkı $P$. parafulva ve $P$. cremicolorata gibi $P$. putida ana dalından dallanarak farklılaşmış yeni türlerden olup balık patojeni olarak tanımlanmış, aynı zamanda kendine özgül bakteriyofajlarının tanımlanması ile hastalık kontrolünde kullanılabileceği önerilmiştir (Park ve ark., 2000). 38 ve 42 numaralı izolatlar ise, aynı oranda (\% 99) P. reidholzensis ve farklı iki mikroorganizma kültür koleksiyonuna [National Board for Respiratory Care (NBRC) ve American Type Culture Collection (ATCC)] ait $P$. putida'nın iki türüne benzerlik göstermiştir. Söz konusu bu izolatlar, $P$. putida ile yakın akrabalıklarının vurgulandığı çalışmalarda degredasyon kabiliyetlerine ek olarak bitki patojenleri ile mücadele eden önemli Pseudomonas türleri olarak tanımlanmışlardır (Rutz ve ark., 2019).

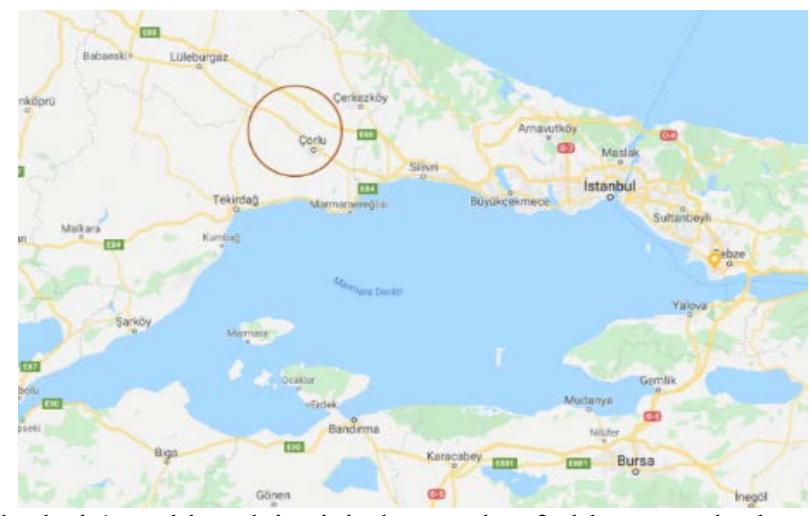

Şekil 1. Örnek toplama bölgeleri (örnekler, daire içinde yer alan farklı tarım alanlarından alınmıştır).

Figure 1. Sample collection sites (samples were collected from different agricultural areas in the circle). 
Çizelge 1. Seçilmiş izolatların kontrol test bakterisi (P. aeruginosa ATCC 15692)'ne göre test sonuçları

Table 1. Test results of selected isolates according to control test bacteria (P. aeruginosa ATCC 15692).

\begin{tabular}{|c|c|c|c|c|c|c|c|c|c|c|c|c|c|c|c|c|}
\hline No & $\begin{array}{c}\text { Gram } \\
\text { boyama }\end{array}$ & Hareketlilik & $\begin{array}{c}\text { Oksidaz } \\
\text { Testi }\end{array}$ & $\mathrm{PO}^{*}$ & GF* & PET* & LET* & $\begin{array}{c}\text { Indol } \\
\mathrm{T}\end{array}$ & $\begin{array}{c}\text { MR } \\
\text { Testi* }\end{array}$ & $\begin{array}{c}\text { VP } \\
\text { Testi* }\end{array}$ & Ni* & $\mathrm{NF}^{*}$ & $\begin{array}{l}\mathrm{PO}_{4} \\
\mathrm{C}^{*}\end{array}$ & $\begin{array}{c}\mathrm{N} \\
\mathrm{A}^{*}\end{array}$ & $\begin{array}{c}\text { Pen } \\
G^{*}\end{array}$ & Pim* \\
\hline $\begin{array}{c}P . \\
\text { aeruginosa } \\
(+\mathrm{K})^{*}\end{array}$ & - & + & + & Pyc/Flr & ++++ & +++ & ++++ & - & - & - & + & ++++ & ++++ & $\mathrm{R}$ & $\mathrm{R}$ & $\mathrm{R}$ \\
\hline 1 & - & + & + & Flr & + & - & + & - & - & - & + & + & - & $\mathrm{R}$ & $\mathrm{R}$ & $\mathrm{R}$ \\
\hline 2 & - & + & + & Pyc & + & - & + & - & - & - & - & + & + & $\mathrm{R}$ & $\mathrm{R}$ & $\mathrm{R}$ \\
\hline 3 & - & + & + & Pyc/ Flr & - & - & + & - & - & - & + & ++ & + & $\mathrm{R}$ & $\mathrm{R}$ & $\mathrm{R}$ \\
\hline 4 & - & + & + & - & + & - & + & - & - & - & + & + & + & $\mathrm{R}$ & $\mathrm{R}$ & $\mathrm{R}$ \\
\hline 5 & - & + & + & $\mathrm{Pyc} / \mathrm{Flr}$ & + & - & + & - & - & - & + & - & + & $\mathrm{R}$ & $\mathrm{R}$ & $\mathrm{R}$ \\
\hline 6 & - & + & + & - & ++ & - & + & - & - & - & + & - & - & $\mathrm{R}$ & $\mathrm{R}$ & $\mathrm{R}$ \\
\hline 7 & - & + & + & - & + & - & + & - & - & - & + & + & + & $\mathrm{R}$ & $\mathrm{R}$ & $\mathrm{R}$ \\
\hline 8 & - & + & + & - & ++++ & + & ++++ & - & - & - & + & + & - & $\mathrm{R}$ & $\mathrm{R}$ & $\mathrm{R}$ \\
\hline 9 & - & + & + & - & - & + & + & - & - & - & - & + & - & $\mathrm{R}$ & $\mathrm{R}$ & $\mathrm{R}$ \\
\hline 10 & - & + & + & - & + & + & + & - & - & - & + & + & ++ & $\mathrm{R}$ & $\mathrm{R}$ & $\mathrm{R}$ \\
\hline 11 & - & + & + & - & + & - & + & - & - & - & + & + & - & $\mathrm{R}$ & $\mathrm{R}$ & $\mathrm{R}$ \\
\hline 12 & - & + & + & Рyc & + & - & + & - & - & - & - & ++++ & + & $\mathrm{R}$ & $\mathrm{R}$ & $\mathrm{R}$ \\
\hline 13 & - & + & + & Рyc & ++++ & ++++ & + & - & - & - & + & + & + & $\mathrm{R}$ & $\mathrm{R}$ & $\mathrm{R}$ \\
\hline 14 & - & + & + & Рус & ++++ & ++++ & + & - & - & - & + & ++++ & ++ & $\mathrm{R}$ & $\mathrm{R}$ & $\mathrm{R}$ \\
\hline 15 & - & + & + & - & + & - & + & - & - & - & - & ++++ & + & $\mathrm{R}$ & $\mathrm{R}$ & $\mathrm{R}$ \\
\hline 16 & - & + & + & Рус & + & - & + & - & - & - & + & + & - & $\mathrm{R}$ & S & $\mathrm{R}$ \\
\hline 17 & - & + & + & Pyc/Flr & + & & + & - & - & - & + & ++ & +++ & $\mathrm{R}$ & $\mathrm{R}$ & $\mathrm{R}$ \\
\hline 18 & - & + & + & - & - & + & + & - & - & - & + & + & ++++ & $\mathrm{R}$ & $\mathrm{R}$ & $\mathrm{R}$ \\
\hline 19 & - & + & + & Рус & + & - & + & - & - & - & + & ++++ & +++ & $\mathrm{R}$ & $\mathrm{R}$ & S \\
\hline 20 & - & + & + & Рyc & - & - & + & - & - & - & + & + & - & $\mathrm{R}$ & $\mathrm{R}$ & $\mathrm{R}$ \\
\hline
\end{tabular}




\begin{tabular}{|c|c|c|c|c|c|c|c|c|c|c|c|c|c|c|c|c|}
\hline No & $\begin{array}{l}\text { Gram } \\
\text { boyama }\end{array}$ & Hareketlilik & $\begin{array}{l}\text { Oksidaz } \\
\text { Testi }\end{array}$ & $\mathrm{PO}$ & GF & PET & LET & $\begin{array}{l}\text { Indol } \\
\mathrm{T}\end{array}$ & $\begin{array}{l}\text { VP } \\
\text { Testi }\end{array}$ & $\begin{array}{l}\text { MR } \\
\text { Testi }\end{array}$ & Nİ & $\mathrm{NF}$ & $\mathrm{PO}_{4} \mathrm{C}$ & NA & $\begin{array}{c}\text { Pen } \\
\text { G }\end{array}$ & Pim \\
\hline 21 & - & + & + & Рyc & - & - & + & - & - & - & + & + & - & $\mathrm{R}$ & $\mathrm{R}$ & $\mathrm{R}$ \\
\hline 22 & - & + & + & - & - & - & + & - & - & - & + & + & - & $\mathrm{R}$ & $\mathrm{R}$ & $\mathrm{R}$ \\
\hline 23 & - & + & + & Рус & + & - & + & - & - & - & - & ++++ & +++ & $\mathrm{R}$ & $\mathrm{R}$ & $\mathrm{R}$ \\
\hline 24 & - & + & + & - & + & - & + & - & - & - & + & + & - & $\mathrm{R}$ & $\mathrm{R}$ & $\mathrm{R}$ \\
\hline 25 & - & + & + & - & + & - & + & - & - & - & + & + & - & $\mathrm{R}$ & $\mathrm{R}$ & $\mathrm{R}$ \\
\hline 26 & - & + & + & Рус & - & - & + & - & - & - & - & + & +++ & $\mathrm{R}$ & $\mathrm{R}$ & $\mathrm{R}$ \\
\hline 27 & - & + & + & Рус & + & - & + & - & - & - & + & + & +++ & $\mathrm{R}$ & $\mathrm{R}$ & $\mathrm{R}$ \\
\hline 28 & - & + & + & Рус & + & ++++ & ++++ & - & - & - & + & ++ & +++ & $\mathrm{R}$ & $\mathrm{R}$ & $\mathrm{R}$ \\
\hline 29 & - & + & + & Рус & + & - & + & - & - & - & + & ++ & + & $\mathrm{R}$ & I & $\mathrm{R}$ \\
\hline 30 & - & + & + & - & + & - & + & - & - & - & + & ++++ & + & $\mathrm{R}$ & $\mathrm{R}$ & $\mathrm{R}$ \\
\hline 31 & - & + & + & Pyc/ Flr & + & - & + & - & - & - & + & ++ & ++ & $\mathrm{R}$ & $\mathrm{R}$ & $\mathrm{R}$ \\
\hline 32 & - & + & + & Pyc/ Flr & - & - & + & - & - & - & + & ++ & +++ & $\mathrm{R}$ & $\mathrm{R}$ & $\mathrm{R}$ \\
\hline 33 & - & + & + & Pyc/ Flr & + & - & + & - & - & - & + & ++ & ++ & $\mathrm{R}$ & $\mathrm{R}$ & $\mathrm{R}$ \\
\hline 34 & - & + & + & Pyc/ Flr & + & - & + & - & - & - & + & ++ & ++ & $\mathrm{R}$ & $\mathrm{R}$ & $\mathrm{R}$ \\
\hline 35 & - & + & + & - & + & - & + & - & - & - & + & + & - & $\mathrm{R}$ & $\mathrm{R}$ & $\mathrm{R}$ \\
\hline 36 & - & + & + & Рyc & + & - & + & - & - & - & + & + & - & $\mathrm{R}$ & $\mathrm{R}$ & $\mathrm{R}$ \\
\hline 37 & - & + & - & - & - & - & + & - & - & - & + & ++ & +++ & $\mathrm{R}$ & $\mathrm{R}$ & $\mathrm{R}$ \\
\hline 38 & - & + & - & Рус & + & - & + & - & - & - & + & ++++ & +++ & $\mathrm{R}$ & $\mathrm{R}$ & $\mathrm{R}$ \\
\hline 39 & - & + & - & Рyc & - & - & + & - & - & - & - & ++ & +++ & $\mathrm{R}$ & $\mathrm{R}$ & $\mathrm{R}$ \\
\hline 40 & - & + & + & Рyc & - & - & + & - & - & - & + & + & +++ & $\mathrm{R}$ & $\mathrm{R}$ & $\mathrm{R}$ \\
\hline 41 & - & + & + & Pyc/Flr & + & - & + & - & - & - & + & ++ & +++ & $\mathrm{R}$ & $\mathrm{R}$ & $\mathrm{R}$ \\
\hline 42 & - & + & + & Рус & + & - & + & - & - & - & + & ++++ & +++ & $\mathrm{R}$ & $\mathrm{R}$ & $\mathrm{R}$ \\
\hline 43 & - & + & + & Рус & + & - & + & - & - & - & + & ++ & ++ & $\mathrm{R}$ & $\mathrm{R}$ & $\mathrm{R}$ \\
\hline 44 & - & + & + & Рус & + & - & + & - & - & - & + & - & ++ & $\mathrm{R}$ & $\mathrm{R}$ & $\mathrm{R}$ \\
\hline 45 & - & + & + & Рус & + & - & + & - & - & - & - & ++++ & + & $\mathrm{R}$ & $\mathrm{R}$ & $\mathrm{R}$ \\
\hline
\end{tabular}

*+K: pozitif kontrol; PO, Pigment oluşumu; GF, Glukozun fremantasyonu; PET; Proteolitik enzim (Kazein) testi; LET, Lipolitik enzim (lipaz) testi; VP, Voges-Preskauer testi; MR, Metil red testi; Ni; Nitrat indirgeme testi; NF, Azot fiksasyonu testi; $\mathrm{PO}_{4}$ Ç, inorganik $\mathrm{PO}_{4}$ indirgeme testi; NA, Nalidiksik Asit; Pen G, Penisilin G; Pim, Pimarisin 
Çizelge 2. 16S rDNA dizi analiz sonuçlarına göre, NCBI veri bankasından elde edilen tanımlama sonuçları ve benzerlik yüzdeleri.

Table 2. According to $16 S$ rDNA sequence analysis results, identification results and maximum identity percentages obtained from NCBI database

\begin{tabular}{|c|c|c|c|}
\hline İzolat No* & Skor & $\begin{array}{c}\text { Benzerlik } \\
\text { Yüzdesi }\end{array}$ & Sonuç \\
\hline 13 & 1434 & $\% 100$ & $\begin{array}{l}\text { P. cremicolorata DSM } 17059 \text { = NBRC } 16634 \\
\text { P. parafulva NBRC } 16636=\text { DSM } 17004 \\
\text { P. putida strain ICMP } 2758\end{array}$ \\
\hline 18 & 1475 & $\begin{array}{l}\% 100 \\
\% 99\end{array}$ & $\begin{array}{l}\text { P. baetica } \\
\text { P. koreensis } \\
\text { P. helmanticensis }\end{array}$ \\
\hline 28 & 1407 & $\% 100$ & $\begin{array}{l}\text { P. plecoglossicida NBRC } 103162 \\
\text { P. cremoricolorata DSM } 17059 \\
\text { P. parafulva NBRC } 16636\end{array}$ \\
\hline 38 & 1389 & \%99 & $\begin{array}{l}\text { P. reidholzensis } \\
\text { P. putida NBRC } 14164 \\
\text { P. putida ATCC } 12633\end{array}$ \\
\hline 42 & 1434 & \%99 & $\begin{array}{l}\text { P. reidholzensis } \\
P \text {. putida NBRC } 14164 \\
P \text {. putida ATCC } 12633\end{array}$ \\
\hline
\end{tabular}

\section{Sonuç}

Çalışma kapsamında başka araştırma konularına yönelik olarak değerlendirilecek toplam 134 izolat elde edilmiştir. Bu izolatlardan 45 tanesi klasik yöntemler kullanılarak 5 tanesi de moleküler teknikler kullanılarak karakterize edilmiştir.

Tanımlanan bu yeni türler tarım alanlarında herbisit ve pestisitlerin biyolojik parçalanmaları başta olmak üzere ve bitki bakteri ilişkilerinin anlaşılmasında yeni çalışma konusu olabilme önemi taşımaktadır. Söz konusu izolatlar ile çalışmaların bir sonraki basamağında tanımlanma çalışmaları özellikle gyr $B$, $r p o B$, $r p o D$ gibi korunmuş gen bölgeleri veya tüm genom dizileme teknikleri kullanılarak derinleştirilecektir. İzolatların yeni biyoformülasyonları preparat haline getirilerek ileride yapılacak çalışmaların materyali olacaktır.

\section{Teşekkür}

Bu araştırma Gebze Teknik Üniversitesi Bilimsel Araştırmalar Birimi tarafından GTÜ BAP 2018 A-105-A-4 no’lu proje ile desteklenmiştir. Sulfonilüre herbisitin çok miktarlarda kullanıldığı tarım alanlarının önceden belirlenmesi, toprak örneklerinin toplanması sırasında arazi sahipleri ile iletişim ve örnekleme bölgelerine ulaşım konusunda rehberlik eden Tekirdağ İl Tarım ve Orman Müdürlüğü personeli Ziraat Mühendisi Ahmet AYVAZ' a çalışmamıza yaptığı destek ve katkıdan dolayı teşekkür ederim.

\section{Kaynaklar}

Alexander, SK., Strete, D. 2001. Microbiology: a photographic atlas for the laboratory, New York: Benjamin Cumings Publication.

Altschul, S. F., Madden, T. L., Schäffer, A. A., Zhang, J., Zhang, Z., Miller, W., Lipman, D. J. 1997. Gapped BLAST and PSI-BLAST: a new generation of protein database search programs. Nucleic acids research, 25(17), 3389-3402. https://doi.org/10.1093/nar/25.17.3389

Atlas, RM. 2004. Parks L.C. (Eds.), Handbook of microbiological media, Second Edition, New York, CRC Press.

Başaran, M.S. 2010. Hububat Alanlarında Uygulanan Sulfonylurea Grubu Bazı Herbisitlerin Minimum Dozlarının Saptanması (Doktora Tezi), Ankara Üniversitesi, Fen Bilimleri Enstitüsü, Bitki Koruma ABD, Ankara.

Bellinder, R. R., Gummesson, G., Karlsson, C. 1994. Percentage driven government mandates for pesticide reduction the Swedish model. Weed Technology 8, 350-359. https://doi.org/10.1017/S0890037X00038914

Blair, A. M., Martin, T. D. 1988. A review of the activity, fate and mode of action of sulfonylurea herbicides. Pesticide Science, 22(3), 195-219. https://doi.org/10.1002/ps.2780220303 
Bolton, E. E., Hepworth, H. M., 1972. Tillage Research in Turkey, Proceedings of Regional Wheat Workshop Beirut, Lebanon.

Brown, H. M. 1990. Mode of action, crop selectivity, and soil relations of the sulfonylurea herbicides, Pesticide Science, 29, 263-281. https://doi.org/10.1002/ps.2780290304

Donald, C. M., 1963. Advances in Agronomy in Competition among crop and pasture plants. 15, NewYork, Academic Press. https://doi.org/10.1016/S0065-2113(08)60397-1

Crimson $^{\mathrm{TM}}$ Taq DNA Polymerase retrieved from: https:/www.uoftmedstore.com/pdfs/CrimsonTaq_MedStore.pdf (2019) (Erişim tarihi: 12.12.2019).

ISO/TS 11059. 2009. (IDF/RM 225: 2009) Milk and milk products - Method for the enumeration of Pseudomonas spp

Johri, A.K., Dua, M., Tuteja, D., Saxena, R., Saxena, D.M., Lal, R. 1996. Genetic manipulations of microorganisms for the degradation of hexachlorocyclohexane, FEMS Microbiology Reviews, 19, 69-84. https://doi.org/10.1111/j.1574-6976.1996.tb00254.x

Kaur, T., Brar, L. S. 2014. Residual effect of sulfonylurea herbicides applied to wheat on succeeding maize. Indian Journal of Weed Science, 46(2), 129-131.

Kwon, S. W., Kim, J. S., Park, I. C., Yoon, S. H., Park, D. H., Lim, C. K., Go, S. J. 2003. Pseudomonas koreensis sp. nov., Pseudomonas umsongensis sp. nov. and Pseudomonas jinjuensis sp. nov., novel species from farm soils in Korea. International journal of systematic and evolutionary microbiology, 53(1), 2. https://doi.org/10.1099/ijs.0.02326-0

Lane, D. J. 1991. Stackebrandt E .(Ed) 16S/23S rRNA sequencing. Nucleic Acid Techniques in Bacterial Systematics, Goodfellow, M., New York, Wiley.

Lopez, J. R., Dieguez, A. L., Doce, A., De la Roca, E., De la Herran, R., Navas, J. I., ... Romalde, J. L. 2012. Pseudomonas baetica sp. nov., a fish pathogen isolated from wedge sole, Dicologlossa cuneata (Moreau). International journal of systematic and evolutionary microbiology, 62(4), 874-882. https://doi.org/10.1099/ijs.0.030601-0

Ma J.P., Wang Z., Lu P., Wang H.J., Waseem Ali S., Li S.P., Huang X. 2009. Biodegradation of the sulfonylurea herbicide chlorimuron-ethyl by the strain Pseudomonas sp. LW3. FEMS Microbiology Letters. 296, $203-20$. https://doi.org/10.1111/j.1574-6968.2009.01638.x

Matsumura, F., Benzet, H. J., Patil, K. C. 1976. Factors affecting microbial metabolism of y-BHC. Journal of Pesticide Science, 1, 3-8. https://doi.org/10.1584/jpestics.1.3

Mitsutomi, Shuhei; Sekimizu, Kazuhisa; Kaito, Chikara 2017. Isolation of antibiotic-producing Pseudomonas species with low-temperature cultivation of temperate soil. Drug discoveries \& Therapeutics, , 11(5): $267-275$.

Pachori P, Gothalwal R, Gandhi P. 2019. Emergence of antibiotic resistance Pseudomonas aeruginosa in intensive care unit; a critical review. Genes Dis. Apr 17;6(2):109-119. https://doi.org/10.5582/ddt.2017.01053

Park, S. C., Shimamura, I., Fukunaga, M., Mori, K. I., Nakai, T. 2000. Isolation of bacteriophages specific to a fish pathogen, Pseudomonas plecoglossicida, as a candidate for disease control. Appl. Environ. Microbiol., 66(4), 1416-1422. http://doi.org/10.1128/AEM.66.4.1416-1422.2000

Peña, A., Busquets, A., Gomila, M., Mulet, M., Gomila, R. M., Reddy, T. B. K., ... ,García-Valdés, E. 2016. High quality draft genome sequences of Pseudomonas fulva DSM 17717 T, Pseudomonas parafulva DSM 17004 T and Pseudomonas cremoricolorata DSM 17059 T type strains. Standards in genomic sciences, 11(1):55. http://doi.org/10.1186/s40793-016-0178-2.

Ramírez-Bahena, M. H., Cuesta, M. J., Flores-Félix, J. D., Mulas, R., Rivas, R., Castro-Pinto, J., ..., Peix, Á. 2014. Pseudomonas helmanticensis sp. nov., isolated from forest soil. International Journal of Systematic and Evolutionary Microbiology, 64(7), 2338-2345. https://doi.org/10.1111/j.1472-765X.2006.02050.X

Rutz, D., Frasson, D., Sievers, M., Blom, J., Rezzonico, F., Pothier, J. F., Smits, T. H. 2019. Comparative genomic analysis of the biotechnological potential of the novel species Pseudomonas wadenswilerensis CCOS 864T and Pseudomonas reidholzensis CCOS 865T. Diversity, 11(11), 204. https://doi.org/10.3390/d11110204

Sözeri, S., Solmaz, A. 1996. Effects of root, leaf and flower extracts of Oriental Lakspur (Consolida orientalis (Gay) Schröd.) on germination and seedling growth of wheat. The Journal of Turkish Phytopathology 25 (3) $89-$ 92.

Uchino M, Shida O, Uchimura T, Komagata K. 2001. Recharacterization of Pseudomonas fulva Iizuka and Komagata, and proposals of Pseudomonas parafulva sp.nov. and Pseudomonas cremocricolorata sp. nov. J Gen Appl Microbiol. ;47:247-61. http://doi.org/10.1186/s40793-016-0178-2

Wada, H., Senoo, K., Takai Y. 1989. Rapid degradation of gamma-HCH in upland soil after multiple applications, Soil Science and Plant Nutrition, 35, 71-77. http://doi.org/10.5897/AJMRx12.001

Waller, G. R. 1989. Allelochemical action of some natural products, in Phytochemical Ecology: Allelochemicals, Mycotoxins and insect Pheromones and Allomones, Institute of Botany, Acedemia Sinica Monogroph Series No:9, Taipei, 129-153s. 
Wasi, S., Tabrez, S., Ahmad, M. 2013. Use of Pseudomonas spp. for the bioremediation of environmental pollutants: a review, Environmental Monitoring and Assessment, 185, 8147-8155. http://doi.org/10.12691/ajmr$\underline{3-4-3}$

Wasi, S., Tabrez, S., Ahmad, M. 2011a. Suitability of Immobilized Pseudomonas fluorescens SM1 Strain for Remediation of Phenols, Heavy Metals, and Pesticides from Water, Water, Air, and Soil Pollution, 220 (1-4), 8899. http://doi.org/10.1007/s11270-010-0737-x

Wasi, S., Tabrez, S., Ahmad, M. 2011b. Detoxification potential of Pseudomonas fluorescens SM1 strain for remediation of major toxicants in Indian water bodies, Water, Air, and Soil Pollution, 222(1-4), 39-51. http://doi.org/10.1007/s11270-011-0802-0.

Williams, M. C. 1984. Poisonous plants part 3, Poisonous alkoloids in plants, Weeds Today, 15: 2, 1-2, (Weed abstr. 33 (6),1755).

Zhang, J.J., Chen, Y.F., Fang, T., Zhou, N.Y., 2013. Co-metabolic degredation of tribenuron methyl, a sulfonylurea herbicide, by Pseudomonas sp. strain NyZ42. International Biodeterioration and Biodegradation. 76, 6-40. https://doi.org/10.1016/j.ibiod.2012.06.019

Zhou, Q.Y., Liu, W.P., Zhang, Y.S., Liu, K.K. 2008. Action mechanisms of acetolactate synthase-inhibiting herbicides, Pesticide Biochemistry Physiology, 89, 89-96. http://doi.org/10.1016/j.pestbp.2007.04.004

Zimdahl, R. L. 2007. Fundamentals of weed science. Elsevier Academic Press. ĠSBN: 978-0-12-372518-9. 